\title{
Research on the mix design of the hot in-place recycling technology and its application
}

\author{
Zheng Yu-xin, Mao Wei, Zhang Feng \\ (Xinjiang Vocational and Technical College of Communications,China Xinjiang Urumqi 831402 ) \\ 1547993443@qq.com
}

\begin{abstract}
KEY WORDS: mix design; hot In-place; asphalt pavement recycling; application
ABSTRACT: From the concept of asphalt pavement recycling technology, The condition of old road is investigated and evaluated, In view of the problems of Urumq, pointed out that the applicable conditions and the advantages and disadvantages of the problems by the materials of Regenerant regeneration performance, new asphalt recycling agent combination of performance and a new set of material dosage various combinations of a large number of tests to analyze studies, preferably comparison to determine asphalt mixture ratio. Introduce construction technology of hot in-place recycling of asphalt pavement, the process of the construction quality control,and analyses the advantages and disadvantages of it.
\end{abstract}

\section{Introduction}

The hot in-place recycling is a kind of technology which can repair the damaged asphalt pavement on the spot technology. Using a large "Asphalt pavement hot in-place recycling integral unit" and heating the old asphalt pavement to the depth required in the design and plowing it up. Then spray appropriate regeneration agent to the old asphalt mixture and then transport then mixture to the continuous agitator of the unit. Through adding new aggregate to add new asphalt and then the material would be translated to the paver and after paving, the roller would be used to roll the road. In the process of the construction of the asphalt pavement which is seriously damaged, the traditional method of milling will cause a waste of a large quantity of the asphalt mixture. These wastes contain asphalt and aggregate at all levels, which not only cause the waste of resources and pollution of the environment, do not meet the concept of "Green transportation "and sustainable development, but also cause the economic losses.

While adopting the hot in -place recycling technology will realize the recycling of the old pavement material, making full use of the "surplus value "of the old pavement. It can promote the recycling of the old pavement materials, reduce the waste of resources and protect the environment.

\section{Road condition survey}

In Urumqi City, every spring season, because of the melting of the snow and the rising of the underground water, the pavement will suffer more freeze-thaw cycles and the traffic will also become heavier, causing the damage of the pavement. Its has seriously affected the normal traffic capacity. Thus, it is a season for the government to repair and maintain the road. Adopting the hot in-place recycling method instead of the traditional method at night will not only have no influence on the normal traffic during the day but also save the raw materials and reduce the cost greatly. In the spring of 2013, In Urumqi City, Kashi Road, Xiamen Road, Satellite Road, BRT No.1 line and the No.3 line and other roads all has been reconstructed through the hot in-place recycling technology. It has achieved good results after two years use.

The hot in-place recycling can be divided into three kinds- Paving hot in-place recycling, Remixing hot in-place recycling and Reshaping hot in-place recycling. After the detailed investigation and comprehensive analysis to the condition of the original road, the damaged condition, the history 
information of the original road and the traffic and the engineering cost, we made evaluation to the loading capacity and damaged condition to the original road. Their SSI are $0.7,0.68,0.72,0.75$ respectively. And the PCI are 32, 35, 33, 31 respectively. We think that the loading capacity of the original road can meet the requirement while the road are seriously damaged. But all these damages happened within $60 \mathrm{~mm}$ of the middle and top layer. The asphalt depth of the original asphalt pavement is thin, which is only $5-9 \mathrm{~cm}$. Combining the climate features and the traffic requirements, after considering a variety of influential factors, we decide the construction method of paving hot in-place recycling.

\section{Mix Design of hot in-place recycling}

The paving hot in-place recycling means that on the basis of reshaping, we will use the loosing equipment to loosen all the old pavements and then mix it with the regeneration material. Using the mixture as the bottom layer and meanwhile, laying a new layer of asphalt material as the top layer(Wearing layer). Thus it can formed a recycling pavement combining the old and new asphalt material. Roll the two layers at the same time. Mix design principle: Recover the performance of the old asphalt to the new asphalt. And the method is to use the specific recycling material and the role of the recycling material is to dissolve and disperse the asphalt.

\section{Inspection of the old asphalt mixture}

Taking the representative RAP sample is the key to the mix design. We should ensure that the sample can fully represent the performance of the RAP to design the regeneration material correctly. Using the method of the combination of construction and maintenance to check whether the materials have difference. And the pavement having obvious difference should be dealt separately. Different areas and conservation areas should not be put together for design. After the representative sampling units are drawn, a detailed sampling plan should be developed before sampling. Choosing a representative sample in the original pavement and remove the inpurity in the sample. There will be a sampling point on average of 500 meters and there will be 10 sampling points totally. Through the extraction test, we can obtain the old asphalt content in asphalt mixture, and recycle the old asphalt. Then do the three index test to the asphalt and test the quality, motivation, kinematic viscosity, the equivalent diameter and other parameters to determine the types of new material and regeneration material. And then do the screening test to the old material sample and draw the gradation curve. Detect the performance of the old asphalt mixture material. See Table 1 for the test results of recycled asphalt material. The components of the recycled asphalt material are shown in table 2.

Table 1 Test results of the recycled asphalt material

\begin{tabular}{|c|c|c|}
\hline Project & Test result & Test method \\
\hline $5^{\circ} \mathrm{C} \quad$ Penetration $(0.1 \mathrm{~mm})$ & 6.4 & Т $0604-2011$ \\
\hline $15^{\circ} \mathrm{C}$ Penetration $(0.1 \mathrm{~mm})$ & 16 & Т $0604-2011$ \\
\hline $25^{\circ} \mathrm{C}$ Penetration $(0.1 \mathrm{~mm})$ & 39 & Т $0604-2011$ \\
\hline Softening point $\left({ }^{\circ} \mathrm{C}\right)$ & 54.4 & Т $0606-2011$ \\
\hline $10^{\circ} \mathrm{C}$ Ductility $(\mathrm{cm})$ & 8.2 & Т $0605-2011$ \\
\hline $15^{\circ} \mathrm{C}$ Ductility $(\mathrm{cm})$ & 14.0 & Т $0605-2011$ \\
\hline $\begin{array}{l}60{ }^{\circ} \mathrm{C} \text { Kinetic viscosity } \\
(\text { Pa.s })\end{array}$ & - & - \\
\hline $\begin{array}{l}135^{\circ} \mathrm{C} \text { Kinematic viscosity } \\
\text { (Pa.s) }\end{array}$ & 1.12 & Т $0625-2011$ \\
\hline
\end{tabular}


Table 2 Components of recycled asphalt

\begin{tabular}{llcl}
\hline Saturates(\%) & Asphaltene (\%) & Aromatics(\%) & Pectin (\%) \\
\hline 33.4 & 17.1 & 11.8 & 37.7 \\
\hline
\end{tabular}

The design is based on the following formula:

$$
\eta_{2}=\eta_{1} \cdot e^{-k \cdot R_{o b}}+e^{-8\left(1-R_{o b}\right)} \cdot \eta_{0}
$$

And:

2 - viscosity of the recycled asphalt $\left(135^{\circ} \mathrm{C}\right.$, Pa.s $)$;

ETA 1 - viscosity of the aging asphalt $\left(135^{\circ} \mathrm{C}\right.$, Pa.s $)$;

$\eta \mathrm{O}$ — viscosity of the regeneration material $\left(135^{\circ} \mathrm{C}, \mathrm{Pa} . \mathrm{s}\right)$

$\mathrm{ROb}$ - optimal dose of regeneration material (\%);

$\mathrm{K}$ - coefficient, for ordinary asphalt $\mathrm{K}=-5$, for SBS modified asphalt $\mathrm{K}=-6$.

The dose of regeneration material of the recycled asphalt is $10 \%$.

In this project, we will prepare the recycled asphalt under the condition of $10 \%$ of the regeneration material and we also tested the performance of the asphalt.See Table 3.

Table 3 Performance of the recycled asphalt

\begin{tabular}{|c|c|c|}
\hline Project & Experimental data & Standard value \\
\hline $\begin{array}{c}25 \\
(0.1 \mathrm{~mm})\end{array}{ }^{\circ} \mathrm{C}$ Penetration & 77 & $60-80$ \\
\hline Softening point $\left({ }^{\circ} \mathrm{C}\right)$ & 48.3 & $\geq 43$ \\
\hline $15^{\circ} \mathrm{C}$ Ductility $(\mathrm{cm})$ & 81.4 & $\geq 40$ \\
\hline $\begin{array}{l}60^{\circ} \mathrm{C} \text { Kinetic viscosity } \\
(\text { Pa.s })\end{array}$ & - & $\geq 180$ \\
\hline Quality loss (\%) & 2.03 & $\leqq \pm 0.8$ \\
\hline Penetration ratio & 0.45 & $\geq 0.54$ \\
\hline Residual ductility & 20.8 & $\geq 15$ \\
\hline
\end{tabular}

\section{Mix design of the asphalt mixture}

Selecting the AC-13C type asphalt mixture to do the mix design of the asphalt and adopting the difference between the passing ratio of the old asphalt mixture and the average passing ratio of the real $\mathrm{AC}-13 \mathrm{C}$ asphalt mixture to make the design and the result is close to the average. Table 4 Results of synthetic gradation.

Table 4 Results of synthetic gradation

\begin{tabular}{|c|c|c|c|c|c|c|}
\hline Model & $\begin{array}{l}10 \mathrm{~mm} \\
\text { macadam }\end{array}$ & $\begin{array}{l}5 \mathrm{~mm} \\
\text { macadam }\end{array}$ & $\begin{array}{l}\text { Machine-ma } \\
\text { de sand }\end{array}$ & $\begin{array}{l}\text { The } \\
\text { stone } \\
\text { chips }\end{array}$ & Breeze & Old asphalt material \\
\hline$\overline{\mathrm{AC}}-13$ & 20 & 10 & 14 & 18 & 4 & 34 \\
\hline
\end{tabular}

Using the extraction method to test the asphalt percentage of the old asphalt mixture and the asphalt-aggregate ratio is $4.35 \%$. Through testing the performance of the asphalt, we find that the asphalt cannot meet the demand. Thus we need to add the regeneration material. After testing the asphalt with $0.44 \%$ regeneration material, the performance of the asphalt can meet the requirement.Referring to the typical asphalt pavement design type of Urumqi, we choose the AC-13C asphalt mixture to do the mix design. And the real asphalt-aggregate ratio of the above two material is $4085 \%$. Thus we decide to add $0.44 \%$ regeneration material and $3.2 \%$ asphalt into the hot in-place 
asphalt mixture.

According to the above mixture ratio, we mixed the AC-13C type asphalt and test the stability of the Markov chain, the flow value, the dynamic stability, the freeze-thaw splitting strength ratio, the residual stability and other indexes were tested. Test result is shown in Table 5. According to the results of laboratory tests, it can be seen that the performance index of hot in-place asphalt mixture can meet the design requirement of the common asphalt mixture.

Table 5 Performance index of the asphalt mixture

\begin{tabular}{ll}
\hline Test items & AC - 13C \\
\hline Average density of gross volume (g/cm3) & 2.472 \\
Markov stability (KN) & 8.65 \\
Flow value (1/10mm) & 26 \\
Residual stability (\%) & 83.7 \\
Freeze-thaw splitting strength ratio (\%) & 96.1 \\
Dynamic stability (time/mm) & 2442 \\
\hline
\end{tabular}

\section{The construction technology of hot in-place recycling}

\section{Construction technology}

The hot in-place recycling technology mainly contains 5 steps: Heat to soften the asphalt. Loosen or remove the surface material. Mix the old material with the regeneration material, the cement and the new asphalt together. Pave the recycled asphalt material on the ground and pave the new asphalt. Level and roll the pavement.

\section{Comparison of technical indexes of hot in-place recycled asphalt}

We used the AC-13C type hot in-place recycled asphalt to pave $16 \mathrm{~km}$ pavement and the application effect is good. We tested and made comparisons to the part adopting the technology and also made comparisons to the original pavement. Then we collect the results and made Table 8 .

Table 6 Comparison of technical indexes of hot in-place recycled asphalt

\begin{tabular}{ccccccc}
\hline Test items & $\begin{array}{c}\text { Average } \\
\text { density of } \\
\text { gross volume } \\
(\mathrm{g} / \mathrm{cm} 3)\end{array}$ & $\begin{array}{c}\text { Markov } \\
\text { stability }(\mathrm{KN})\end{array}$ & $\begin{array}{c}\text { Flow value } \\
(1 / 10 \mathrm{~mm})\end{array}$ & $\begin{array}{c}\text { Residual } \\
\text { stability } \\
(\%)\end{array}$ & $\begin{array}{c}\text { Freeze-thaw } \\
\text { splitting } \\
\text { strength } \\
\text { ratio }(\%)\end{array}$ & $\begin{array}{c}\text { Dynamic } \\
\text { stability } \\
\text { (time } / \mathrm{mm})\end{array}$ \\
\hline $\begin{array}{c}\text { Safety } \\
\text { specification } \\
\text { requirements } \\
\text { AC - 13C hot } \\
\text { in-place } \\
\text { recycling } \\
\text { type }\end{array}$ & 2.442 & 8.66 & 26.1 & 83.6 & 96.0 & 2445 \\
$\begin{array}{c}\text { Common AC } \\
-13 \mathrm{C}\end{array}$ & 2.451 & 10.2 & 21.5 & 90.2 & 80.5 & 1648 \\
\hline
\end{tabular}




\section{Conclusion}

Compared with the traditional methods, the hot in-place recycling technology has many advantages, which can guarantee the normal traffic of the day, save a large quantity of construction materials. In addition, through the application on the pavements of Urumqi, we also summed up its technical features, advantages as follows:

1) Good for the combination of the asphalt surface layers.

2) Good for the recovery of the gaps between the layers without hot in-place recycling asphalt

3 ) Improve the gradation of the asphalt surface, increase the density of the asphalt surface and delay the aging of the asphalt pavement.

4) Restore the flexibility and the performance of the asphalt

But there are also some shortcomings, which need further studying.

1) Not suitable for the road with too thin As surface or low loading capacity.

2) Because of the length of the construction unit, a longer working place is needed. Its is difficult to construct the road with heavy traffic, while constructing at night will also cause difficulty in controlling the quality.

3 ) The pollution is serious. The asphalt surface needs heating and the construction unit needs fuel, which will produce a certain amount of waste gas. Besides, constructing at night will cause some noise pollution.

4) Because of the milling of the old pavement, there will be some damage of the asphalt pavement, which will change the original materials of the old pavement.

\section{Reference}

[1] Wang Haijun. Research on the application of the hot in-place recycling technical on the urban road [D], Shenyang Jianzhu University,, 2013

[2] Zhu Jianhua. Research on the treatment of the damage of highway by the technology of hot in-place recycling [D]. Nanjing Forestry University, 2012

[3] Gao Jin. Research on the application of hot in-place recycling technology in Jilin province [D], Chang'an University, 2013

[4] Liu Lin; Gao Jiyang, Study on asphalt of the hot in-place recycling pavement [J], Highway engineering, 2011,23(2) $140 \sim 142$

[5] Huang Jun; Fan Xiaoxu; Sun Xiaofeng; Li Hailong, Application of the hot in-place recycling technology on the maintenance of the asphalt pavement [J], Road machinery and construction mechanization, 2012,22 (12), $49 \sim 51$

[6] Xu Shifa;Xu Liting; Zheng Wei; Wang Xiaoxiao,Hot in-place recycling technology and its future development [J], Road machinery and construction mechanization, 2013,30 (6), $39 \sim 43$ 